This is the author's final, peer-reviewed manuscript as accepted for publication. The publisher-formatted version may be available through the publisher's web site or your institution's library.

\title{
Consumer sensory analysis of high flavonoid transgenic tomatoes
}

Wansang Lim, Rebecca Miller, Jungeun Park, Sunghun Park

\section{How to cite this manuscript}

If you make reference to this version of the manuscript, use the following information:

Lim, W., Miller, R., Park, J., \& Park, S. (2014). Consumer sensory analysis of high flavonoid transgenic tomatoes. Retrieved from http://krex.ksu.edu

\section{Published Version Information}

Citation: Lim, W., Miller, R., Park, J., \& Park, S. (2014). Consumer sensory analysis of high flavonoid transgenic tomatoes. Journal of Food Science, 79(6), S1212-S1217.

Copyright: $@ 2014$ Institute of Food Technologists ${ }^{\circledR}$

Digital Object Identifier (DOI): doi:10.1111/1750-3841.12478

Publisher's Link: http://onlinelibrary.wiley.com/doi/10.1111/1750-3841.12478/full

This item was retrieved from the K-State Research Exchange (K-REx), the institutional repository of Kansas State University. K-REx is available at http://krex.ksu.edu 


\section{Full Title}

Consumer Sensory Analysis of High Flavonoid Transgenic Tomatoes

\section{Name(s) of Author(s)}

Wansang Lim ${ }^{1}$, Rebecca Miller ${ }^{2}$, Jungeun Park ${ }^{1}$, Sunghun Park ${ }^{1}$

\section{Author Affiliation(s)}

${ }^{1}$ Department of Horticulture, Forestry and Recreation Resources, Kansas State University, Manhattan, KS 66506

${ }^{2}$ Department of Grain Science and Industry, Kansas State University, Manhattan, KS 66506 Sunghun Park, 3731 Throckmorton Kansas State University Manhattan, KS 66506 Phone: (785) 5324412 (office), Fax: (785) 532-6949, E -mail: shpark@ksu.edu

\section{ABSTRACT:}

Tomatoes have ameliorative effects on cardiovascular disease and cancer (Agarwal and Rao 2000; Rao 2002). In this study, metabolic engineering of flavonoids was utilized to improve the nutritional value of tomatoes by increasing flavonol and anthocyanin content. Total flavonol content was significantly increased in both the peel and flesh using the onion chalcone isomerase (CHI) gene. The Delila (Del) and Rosea1 (Ros1) genes from the snapdragon Antirrhinum majus were concomitantly expressed to produce an anthocyanin-rich tomato which was purple in color. Sensory evaluation by a panel of 81 untrained consumers revealed no significant difference in liking of color or texture between $\mathrm{CHI}$, Del/Ros1, and wild-type tomatoes. Consumers reported marginal but significantly higher preference for the flavor and overall liking of $\mathrm{CHI}$ tomatoes over Del/Ros1 and wild-type tomatoes. This study is the first to report the results of sensory tests of transgenic tomatoes by a consumer panel representing the general consuming public. 


\section{Keywords:}

flavonoids, transgenic, liking, tomato, sensory

\section{Introduction}

Tomatoes are a good source of lycopene, vitamin C, vitamin E, and carotenoids (Hernandez and others 2007). However, tomatoes have relatively small amounts of flavonoids compared with other vegetables (Butelli and others 2008). Flavonoids are a subclass of plant polyphenols, which have a wide range of health-promoting effects (Wach and others 2007; Luo and others 2008). Flavonol and anthocyanin, subclasses of flavonoids, are especially well-known as health-protecting components of the human diet and offer many pharmacological benefits including protection against various types of cancer cells, chronic obstructive pulmonary disease, diabetes and vascular disease (Ghosh and Konishi 2007).

Genetic engineering is an effective method for enhancing the flavonoid content of fruits and vegetables (Bovy and others 2007). A single $\mathrm{CHI}$ gene from Petunia hybrida suffices to increase flavonol content in tomato peel (Colliver and others 2002) while Delilah (Del) and Rosea1 (Ros1) genes extracted from snapdragon were stacked and introduced to tomatoes, resulting in an increased anthocyanin content and purple colored tomato peel (Butelli and others 2008).

Consumers generally have formed negative but vague perceptions of transgenic foods which prevent them from knowingly purchasing such products. Transgenic vegetables and crops are widely grown and consumed in the United States and are gradually being accepted in other parts of the world (Nap and others 2003). The Grocery Manufacturers of America 
estimated in 2003 that $75 \%$ of all processed foods in the United States contain at least one GMO ingredient (Bren 2003). Between 1997 and 2010, the total surface area of cultivated land being used to grow genetically modified organisms (GMO) increased from $17,000 \mathrm{~km}^{2}$ to $1,480,000 \mathrm{~km}^{2}$, resulting in approximately $10 \%$ of the world's croplands planted with GMO crops in 2010 (Bren 2003; James 2011). Consumers perceive non-transgenic foods to be more environmentally friendly and safer than transgenic foods (Nap and others 2003; Anderson and others 2007; Curtis and others 2004). However, recent studies reflect a new willingness on the part of consumers to buy transgenic vegetables, preferring those that contain a gene or genes taken from other vegetables rather than from Arabidopsis or other species (Lusk and Rozon 2006). While these developments in the consumer marketplace have been unfolding, there have been almost no attempts to conduct consumer taste tests with transgenic tomatoes. The few tests that have been conducted involved transgenic tomatoes that were tested by trained professionals or small consumer groups with no controls for differences in sample demographics (Bartoszewski and others 2003; Davidovich-Rikanati and others 2007).

In this study, the flavonol and anthocyanin contents of tomatoes were increased using transgenic methods. The color, flavor, texture, and overall liking of these transgenic tomatoes compared to wild-type tomatoes were evaluated by an untrained consumer panel.

\section{Materials and Methods}

\section{Vector construction}

Onion (Allium cepa L.) ranks highest in flavonol content among vegetables and fruits (Haytowitz and others 2013), therefore the $\mathrm{CHI}$ gene from onion was used to increase flavonol 
content. The $\mathrm{CHI}$ gene was isolated and cloned from red onions. The sequence was obtained by the accession number, AY700851.1 in NCBI (Kim and others 2004b). In a separate trial, Delila (Del) and Rosea1 (Ros1) genes from snapdragon Antirrhinum majus were used to increase anthocyanin content.

The RNA was extracted with an RNeasy plant mini-kit from QIAGEN (Valencia, CA, U.S.). cDNA was made with an Advantage RT-for-PCR Kit from Clontech (Mountain View, CA, U.S.). The primer sequences for $\mathrm{CHI}$ were $\mathrm{CHI}$ forward 5' -ATGGAAGCAGTGACAAAGTT -3' and CHI reverse 5' - T CATGAAAGCACCGGTAACT - 3'. The PCR product was inserted to pE1775 expression vector (Lee and others 2007). The pE1775 vector harboring $\mathrm{CHI}$ gene was transferred to Agrobacterium (LBA4404) using the freeze-thaw method (Holsters and others 1978). The Del/Ros1 vector harboring Del/Ros1 gene was obtained from Butelli (Butelli and others 2008).

\section{Plant Transformation}

Seeds of the Solanum lycopersicum L. were surface-sterilized and germinated on a Murashige and Skoog inorganic salt medium (Murashige and Skoog 1962). Tomato transformation was performed via an Agrobacterium-mediated transformation method using cotyledon and hypocotyl explants, as described in Park and others (2003). Agrobacterium tumefaciens LBA 4404 was used to generate stable transgenic plants. Following inoculation with A. tumefaciens, the plant cultures were maintained at $25^{\circ} \mathrm{C}$ under a 16 hour photoperiod. After 6 to 8 weeks, the regenerated shoots were transferred to a rooting 
medium for 6 weeks. The temperature in the greenhouse was maintained within a range of $25^{\circ} \mathrm{C}$ to $30^{\circ} \mathrm{C}$. The $\mathrm{cv}$. Rubion was used for all transformation.

\section{Transgenic plant analyais}

Genomic tomato DNA was extracted from leaf tissue with a Qiagen Plant DNA extraction kit. Tomato RNA was extracted from the peel with a Qiagen Plant RNA extraction kit. The cDNA was synthesized by moloney murine leukaemia virus-reverse transciptase (BD Biosciences Clontech, Palo Alto, CA, USA). All polymerase chain reactions (PCR) including RT-PCR were performed with a GoTaq Flexi DNA Polymerase kit (Promega Corporation, Madison, WI, USA). The RT-PCR primer sequences for $\mathrm{CHI}$ were same with the primers used for cloning. The RT-PCR primer sequences for Del/Ros1 were forward 5' - AGGGAAATGGCATCAAGT - 3' and reverse 5' ATTCTACCAGCAATCAGC 3'. All PCRs for genomic DNA and cDNA were performed following manufacture's instruction.

\section{Flavonol and anthocyanin content measurement}

To extract flavonoids in the peel, an outer layer with a thickness of about $1 \mathrm{~mm}$ was separated from the fruit. The cuticula, an epidermal layer, plus some sub-epidermal tissue were also removed to form the peel tissue used in the experiment. The columella was excised from the remaining flesh tissue. The seeds and jelly-like parenchyma were removed from the tissue that remained after separating the peel and were classified as flesh. Following separation, both peel and flesh tissues were frozen in liquid nitrogen and stored at $-80{ }^{\circ} \mathrm{C}$ (Colliver and others 2002) until they were processed for analysis. 
To measure total flavonol content, $1 \mathrm{~g}$ of peel or flesh stored in $-80^{\circ} \mathrm{C}$ were macerated in a round-bottom $15 \mathrm{ml}$ tube with an iron rod. The samples were then mixed with $2 \mathrm{~mL}$ of methanol 75\% (1.5 mL methanol, and $0.5 \mathrm{~mL}$ ultrapure water at $\mathrm{pH} 2.5$ adjusted with TFA), placed in an ultrasound bath at $40{ }^{\circ} \mathrm{C}$ for $30 \mathrm{~min}$, then centrifuged at 3,500 rpm. The supernatant was carefully recovered to prevent contamination with the homogenized tomato puree pellet and was passed through a 0.45 filter $\mu \mathrm{m}$ GHP (Waters, Millford, MA, USA) (Hernandez and others 2007). Flavonol content was measured spectrophotometrically at 361 $\mathrm{nm}$ with the NanoDrop Photospectrometer (Thermo Scientific, Wilmington, DE, USA). Rutin (Sigma-Aldrich, St. Louis, MO, USA) was used as the standard. Each sample was evaluated in triplicate.

Anthocyanin content was measured using the following procedure adapted from Solfanelli and others (2006). One gram of peel or flesh was ground in the same manner as for total flavonol extraction. The samples were then mixed with $2 \mathrm{~mL}$ of $0.5 \%(\mathrm{v} / \mathrm{v}) \mathrm{HCl}$ solution in methanol. The same volume of chloroform was added to the extract to remove chlorophylls. The mixture was centrifuged for $1 \mathrm{~min}$ at $14,000 \times \mathrm{g}$. The anthocyanin-containing phase was recovered and absorption was determined spectrophotometrically at $544 \mathrm{~nm}$ with the NanoDrop Photospectrometer (Thermo Scientific, Wilmington, DE, USA). Delphinidin 3rutinoside (APin Chemicals LTD, Abingdon, UK) was used as the standard control. Each sample was evaluated in triplicate.

Standard curves were prepared for both rutin and delphinidin 3-rutinoside. When necessary, samples used for measuring total flavonol and anthocyanin were diluted to measurable concentrations in UV absorbance ranges of 0.09-0.6 and 0.08-0.6. 


\section{Consumer evaluation}

Tomatoes were harvested 20 days after the breaker stages and 1 day before the sensory test. Immediately after harvest, the tomatoes were washed under tap water, dried with kitchen towels and stored in sealed plastic containers at $4^{\circ} \mathrm{C}$ overnight. Four hours before the sensory test, the plastic containers were placed at room temperature $\left(24^{\circ} \mathrm{C}\right)$. Immediately before serving, the tomatoes were cut into $6 \mathrm{~mm}$-thick slices.

Consumer tests were carried out on the campus of Kansas State University. All consumers were recruited from the Kansas State University area (Manhattan, Kansas, U.S.A). This research was intended to elicit the opinions of ordinary consumers, not experts in food science or culinary science. The only criterion applied in recruiting participants was that they be willing to consume transgenic food during the study. All recruited consumers consume fresh and processed tomato at least once per month, regularly.

Prior to participation, each consumer signed an informed consent form indicating that they were aware that they would be consuming transgenic tomatoes in the evaluation. The sensory test was conducted in a single session on a single day by 81 untrained consumers.

Each consumer received a paper plate containing 1 slice each of the high flavonol, high anthocyanin and wild-type (non transgenic) tomatoes. The samples were coded with a randomized three-digit number and presented in random order to eliminate presentation bias. Consumers were instructed to taste the tomatoes in order from left to right and score each one independently on how much they liked the color, flavor, and texture as well as overall liking of each tomato. A 7-point hedonic scale was used for each attribute where $7=$ like extremely, $4=$ 
neither like nor dislike and 1 = dislike extremely. Ripeness was scored on a 7-point scale where $7=$ overly ripe, 4 = perfectly ripe and 1 = under ripe. The typical hedonic scales are 5 to 9 point scale (Cruz and others 2010). The 7-point scale makes easier for untrained participants than the 9 point scale (Lawless and Heymann 2010). It has been shown that consumers rarely use the end anchors of a 9-point scale because they are too extreme (Moskowitz and others 2003). Unsalted soda crackers and room temperature water were provided as palate cleansers between each tomato. After completing the sensory evaluation, consumers were asked to answer demographic questions which included age, gender, education level, liking of raw tomatoes, frequency of raw tomato consumption and whether they would purchase and consume transgenic foods if they were shown to be healthier than non-transgenic foods. Additionally, consumers were asked to rate their comfort level with eating transgenic foods before as well as after participating in the sensory test using a 5-point scale where 1= not comfortable at all, $3=$ not sure and $5=$ completely comfortable. Our object in so doing was to compare changes in attitude before and after consuming transgenic food rather than measuring consumer perceptions. The 5 point scale should be enough for that purpose.

To minimize the effect of the purple color, which could affect the perceived flavor, taste, and overall liking of the samples, the tomatoes were placed randomly and consumers were instructed not to compare them.

\section{Statistical analysis}

All data were analyzed using SAS (Version 9.1, Cary, N.C., USA). For mean separation, Tukey's test was used. Analysis of variance was performed using the GLM procedure. 
Statistically significant differences were determined at the $95 \%$ confidence level $(P<0.05)$. For the sensory test, ripeness was used as a covariate.

\section{Results and Discussion}

At the phenotypic level, there was no difference in appearance and fruit weight between the wild-type, high flavonol $(\mathrm{CHI})$ and high anthocyanin (Del/Ros1) tomatoes other than color (Fig 1). The average individual fruit weight was $47 \pm 2.6$ (standard error) g. The wildtype and $\mathrm{CH} /$ tomatoes were the typical red color while both the peel and the flesh of the Del/Ros1 tomatoes were purple.

The segregation ratios for all 6 transgenic lines for $\mathrm{CHI}$ and Del/Ros1 were 3:1 at T1 generation. $\mathrm{CHI}(\mathrm{CHI}-4, \mathrm{CHI}-6$ and $\mathrm{CHI}-8)$ and Del/Ros1 (DR-4, DR-5 and DR-7) genes were recovered from the transformation process. All transgenic tomatoes were checked by genomic DNA amplification (Fig 2a). Once the transgenic plants had the gene of interest, all were expressed for both peel and flesh without exception (Fig 2 b and c). There was no distinguishable difference between lines regardless of the flavonoid content in either the peel or the flesh.

\section{Flavonol and anthocyanin contents}

All genes showed significant differences between genes in total flavonol and total anthocyanin content in the peel and flesh. Onion $\mathrm{CHI}$ from cDNA by RT-PCR was amplified. The resulting lines exhibited a substantial increase in flavonol content. On average, total flavonol content of the peel was increased by 2.3-fold in the Del/Ros (DR) lines and 9.8 fold in the CHI 
lines compared to the wild-type tomatoes (Fig 3a). While total flavonol content of the flesh was barely detectable in the wild type, the levels were significantly increased, by 35 -fold and 96 -fold on average, in the Del/Ros1- and $\mathrm{CHI}$-expressing lines, respectively (Fig 3b).

Previous attempts by others to enhance flavonoid content by manipulating structural or regulatory genes found that a major limiting factor along the flavonoid biosynthetic pathway was the lack of expression of the $\mathrm{CHI}$ gene in the tomato peel, likely caused by a mutation in the promoter (Gonzali and others 2009). Reintroduction of the expression of the $\mathrm{CHI}$ gene in cultivated tomato fruit can be achieved by interspecific crosses with wild tomato species or ectopic expression of $\mathrm{CHI}$ isolated from other species (Willits and others 2005; Muir and others 2001). A single $\mathrm{CHI}$ gene suffices to increase flavonol content in tomato peel (Colliver and others 2002). Although the chalcone synthase (CHS), CHI, flavanone-3-hydroxylase (F3H) and flavonol synthase (FLS) genes were ectopically expressed simultaneously, the flavonol content of the tomato with the four genes was not significantly increased compared with tomatoes in which only the $\mathrm{CHI}$ gene was expressed. Without the $\mathrm{CHI}$ gene, the single expression of the $\mathrm{CHS}$, $F 3 H$, and $F L S$ genes were also not effective. The concomitant expression of the four genes was required to increase the flavonol content of the flesh (Colliver and others 2002). In northern blot analysis, Muir and others (2002) detected no expression of endogenous $\mathrm{CHI}$ in tomato flesh. However, onion $\mathrm{CHI}$ was amplified by RT-PCR (Fig 2). Thus, ectopic expression of $\mathrm{CHI}$ produced higher flavonol content in the flesh than diffusion from the peel to the flesh. However, the increase in flavonol content in the $\mathrm{CHI}$ transgenic tomato was significantly lower than in the flesh of the Del/Ros1 transgenic tomatoes. Further experimentation with other cultivars will be needed to explain this result. Differential increases in flavonol content 
corresponding to different cultivars were reported by Luo and others (2008) in transgenic tomatoes by expressing AtMYB12, resulting in approximately twice as much rutin and Kaempferol rutinoside in the Micro Tom cultivar compared with the Money Maker cultivar. The difference in flavonol content between wild-type cultivars was greater than that between transgenic cultivars (Luo and others 2008). Perhaps the initial flavonol content in wild-type tomatoes could be the factor that determines flavonol content after transformation. In wildtype tomatoes, there is an approximately 10 -fold difference in flavonol content between cultivars (Verhoeyen and others 2002).

Both the peel and flesh of the wild-type and $\mathrm{CH}$ I tomatoes contained essentially no traceable amount of anthocyanin (Fig. 3c and d). The anthocyanin content of the Del/Ros1 (DR) lines was significantly higher than in wild type and $\mathrm{CHI}$ tomatoes $(\mathrm{p}<0.01)$. The anthocyanin content of the peel ranged from $0.5-0.9 \mathrm{mg} / \mathrm{g}$ while that of the flesh ranged from $0.03-0.08$ $\mathrm{mg} / \mathrm{g}$. The DR-5 and DR-7 lines exhibited significantly higher anthocyanin content compared with the DR-4 line for both peel and flesh ( $p<0.03$ and 0.01 , respectively, Fig. $3 c$ and d).

Delilah (Del) and Roseal (Ros1) genes extracted from snapdragon were stacked and introduced into tomatoes to produce a purple color in the tomato peel (Butelli and others 2008). Regulator genes offer the advantage of upregulating many genes at once along the flavonoid pathway (Bren 2003). Butelli (2008) reported that the expression of Del/Ros upregulates $P A L, C H I$, and $F 3 H$. PAL determines the flavonoid flux and may explain the increase in flavonol content in both the peel and the flesh beyond the elevated anthocyanin content. The upregulation of $D F R$ (dihydroflavonol reductase) affects the distribution of flavonol and anthocyanin content (Kim and others 2004a). Even though Butelli (2008) reported the Del/Ros1 
upregulated $D F R$, the effect may not have been strong enough to use all the flavonol flux that is necessary to convert to anthocyanin.

The maze transcription factor $L C / C 1$ gene upregulates necessary structural genes along the flavonoid pathway, increasing the high flavonol content in tomato flesh (Bovy and others 2002). However, the fruit color remains red in spite of the increase in anthocyanin content because it does not upregulate the PAL gene. The high flavonol content might also be explained by substrate specificity. Bovy et al. (2002) reported that tomato DFR cannot use dihyrdokaempferol and dihydroquercetin, so unconverted dihyrdokaempferol and dihydroquercetin in the tomato fruit are finally converted to a further glycosylated form of kaempferol, quercertin, kempferol glycoside, and rutin. Rutin is the most abundant flavonol in wild-type tomatoes. The upregulated DFR by Del/Ros1 eventually moves to anthocyanin. DFR is located at the branch point between flovonol and anthocyanin, enabling it to determine how much of these substances remain.

\section{Consumer evaluation}

Acceptance of color, flavor, texture, and overall liking of the tomatoes were evaluated by an untrained panel of 81 consumers. The size of the panel was appropriate for consumer hedonic tests (Lawless and Heymann 1999, Hough et al 2006). The panel was comprised of 38 females (47\%) and 43 males (54\%). The ages of the panelists were equally distributed between the three age ranges of 18-25 yrs old (32\%), 26-40 yrs old (33\%), 41-55 yrs old (27\%) and over 56 years old (8\%). On average, typical tomato consumption was reported as daily for $17 \%$, once 
per week for $39 \%$, up to 3 times per month for $30 \%$ and less than 1 time per month for $14 \%$ of the panelists.

Consumer evaluation revealed no bias toward red tomatoes, as the color-liking score of the high-anthocyanin (Del/Ros1) purple tomato was not significantly different from those of the two red tomatoes (Table 1). Additionally the flavor-, texture-, and overall-liking scores of the Del/Ros1 tomatoes were similar to those of the wild-type tomato. The color-and texture-liking scores of the high flavonol $(\mathrm{CHI})$ tomato were similar to those of the other two tomatoes; however, on flavor and overall liking they were slightly but significantly better. Even though the sample size was adequate to detect statistical differences between the three groups in the sample (wild, high flavonol, and high anthocyanin plants), if we consider the variations in the consumer subgroups the size of the sample may not be adequate for analyzing the statistically significant variances between subgroups by age, gender, or consumption frequency. However, among all subgroups, the overall liking of the Del/Ros1 tomato was consistently higher than that of the $\mathrm{CHI}$ tomato even though no statistical difference was found. P-values for the effects on overall liking are $0.82,0.56$, and 0.33 for the $18-25,26-40$, and over-40 age groups, respectively; 0.52 and 0.87 for the female and male groups, respectively; and 0.30, 0.72, 0.09, and 0.32 for the daily, once per week, up to 3 times per month, and less than 1 time per month subgroups, respectively.

The tomatoes were grown under strictly controlled conditions in greenhouses to avoid environmental stress because flavonoids help plants cope with such stress. Controlled greenhouse environments make it possible to obtain consistent quality and ripeness in tomatoes. The ripeness of a tomato affects its taste (Kader and others 1977). Therefore, 
ripeness was used as a covariate. There were no significant differences in any of the parameters measured attributable to consumers' perceived ripeness (Table 1).

Consumers reported their comfort level with eating transgenic food before and after the taste test using a 5 -point scale where $1=$ not comfortable at all, $3=$ not sure and $5=$ completely comfortable. Prior to participating in the sensory test, the overall average panelist comfort level with transgenic food consumption was high, receiving a score of 4.3 out of 5 . After knowingly consuming transgenic tomatoes in the sensory test, the average comfort level increased to 4.5. Participating in the sensory test did not affect the comfort level of the majority of the panelists (85\%). However, $14 \%$ of the panelists became more comfortable while only 1 participant (1\%) felt less comfortable with transgenic food consumption after testing $(p<0.01$ by chi square test). The reason for this change in comfort level was not given. A high percentage of the panelists (96\%) indicated they would purchase and consume transgenic foods if they were shown to be healthier than non-transgenic foods.

\section{Conclusion}

Using transgenic methods, the $\mathrm{CHI}$ gene from red onion and Del/Ros1 genes from snapdragon were used to increase the flavonol and anthocyanin contents, respectively, of tomatoes. An untrained consumer panel indicated no difference in liking of color or texture among the high flavonol, high anthocyanin, and wild-type tomatoes. However, the flavor and overall liking of the high flavonol tomatoes was slightly but significantly higher than that of the other tomatoes. Although there is considerable controversy over the benefits, costs, and hazards of genetically engineered food, $96 \%$ of the consumers on the panel reported that they 
would buy transgenic food if they. Indeed, following the test, $14 \%$ of the panelists changed their attitudes positively toward believed that it would promote health. This is important for the future of developing transgenic vegetables transgenic vegetables.

\section{References}

Agarwal S, Rao AV. 2000. Tomato lycopene and its role in human health and chronic diseases. CMAJ 163(6):739-44.

Anderson JC, Wachenheim CJ, Lesch WC, Perceptions of Genetically Modified and Organic Foods and Processes. 2007 [Accessed 201312 30] Available from: http://www.agbioforum.org/v9n3/v9n3a05-wachenheim.htm.

Bartoszewski G, Niedziela A, Szwacka M, Niemirowicz-Szczytt K. 2003. Modification of tomato taste in transgenic plants carrying a thaumatin gene from Thaumatococcus daniellii Benth. Plant Breed. 122(4):347-51.

Bovy A, de Vos R, Kemper M, Schijlen E, Pertejo MA, Muir S, Collins G, Robinson S, Verhoeyen M, Hughes S, Santos-Buelga C, van Tunen A. 2002. High-flavonol tomatoes resulting from the heterologous expression of the maize transcription factor genes LC and C1. Plant Cell 14(10):2509-26. 
Bovy A, Schijlen E, Hall RD. 2007. Metabolic engineering of flavonoids in tomato (Solanum lycopersicum): the potential for metabolomics. Metabolomics 3(3):399-412.

Bren L, Genetic Engineering: The Future of Foods? ; 2003 [Accessed 2012 2/10] Available from: http://permanent.access.gpo.gov/lps1609/www.fda.gov/fdac/features/2003/603_food.html.

Butelli E, Titta L, Giorgio M, Mock H-P, Matros A, Peterek S, Schijlen EGWM, Hall RD, Bovy AG, Luo J, Martin C. 2008. Enrichment of tomato fruit with health-promoting anthocyanins by expression of select transcription factors. Nat. Biotechnol. 26(11):1301-8.

Colliver S, Bovy A, Collins G, Muir S, Robinson S, de Vos CHR, Verhoeyen ME. 2002. Improving the nutritional content of tomatoes through reprogramming their flavonoid biosynthetic pathway. Phytochem Rev 1:113-23.

Cruz AG, Cadena RS, Walter EHM, Mortazavian AM, Granato D, Faria JeAF, Bolini HMA. 2010. Sensory Analysis: Relevance for Prebiotic, Probiotic, and Synbiotic Product Development. CRFSFS 9:358-73.

Curtis KR, McCluskey JJ, Wahl T, Consumer Acceptance of Genetically Modified Food Products in the Developing World. 2004 [Accessed 2013 12/30] Available from: http://www.agbioforum.org/v7n12/v7n12a13-mccluskey.htm. 
Davidovich-Rikanati R, Sitrit Y, Tadmor Y, lijima Y, Bilenko N, Bar E, Carmona B, Fallik E, Dudai N, Simon JE, Pichersky E, Lewinsohn E. 2007. Enrichment of tomato flavor by diversion of the early plastidial terpenoid pathway. Nat. Biotechnol. 25(8):899-901.

Ghosh D, Konishi T. 2007. Anthocyanins and anthocyanin-rich extracts: role in diabetes and eye function. Asia Pac. J. Clin. Nutr. 16(2):200-8.

Gonzali S, Mazzucato A, Perata P. 2009. Purple as a tomato: towards high anthocyanin tomatoes. Trends Plant Sci 14(5):237-41.

Haytowitz DB, Eldridge AL, Bhagwat S, Gebhardt SE, Holden JM, Beecher GR, Peterson J, Dwye J, Development of a multi-nutrient data quality evaluation. USDA; 2013 [Accessed 20131228 Available from: http://www.nal.usda.gov/fnic/foodcomp/Data/Other/AICR03_VegFlav.pdf. Hernandez M, Rodriguez E, Diaz C. 2007. Free hydroxycinnamic acids, lycopene, and color parameters in tomato cultivars. J Agri Food Chem 55(21):8604-15.

Holsters M, Dewaele D, Depicker A, Messens E, Vanmontagu M, Schell J. 1978. Transfection and transformation of Agrobacterium-tumefaciens. Mol. Gen. Genet. 163(2):181-7.

James C, Biotech Crops Surge Over 1 Billion Hectares Developing nations drive growth at adoption rates exceeding industrialized countries. International service for the acquistion of agri-biotech applications; 2011 [Accessed 2012 02/07] Available from:

http://www.isaaa.org/resources/publications/briefs/42/pressrelease/default.asp. 
Kader AA, Stevens MA, Albrightholton M, Morris LL, Algazi M. 1977. Effect of fruit ripeness when picked on flavor and composition in fresh market tomatoes. J. Am. Soc. Hortic. Sci. 102(6):724-31.

Kim S, Binzel ML, Park S, Yoo K-S, Pike LM. 2004a. Inactivation of DFR (Dihydroflavonol 4reductase) gene transcription results in blockage of anthocyanin production in yellow onions (Allium cepa). Molecular Breeding 2004:253-63.

Kim S, Jones R, Yoo KS, Pike LM. 2004b. Gold color in onions (Allium cepa): a natural mutation of the chalcone isomerase gene resulting in a premature stop codon. MoL Gen Genomics 272(4):411-9.

Lawless HT, Heymann H. 2010. Sensory Evaluation of Food: Principles and Practices: Springer New York.

Lee LY, Kononov ME, Bassuner B, Frame BR, Wang K, Gelvin SB. 2007. Novel plant transformation vectors containing the superpromoter. Plant Physiol 145(4):1294-300.

Luo J, Butelli E, Hill L, Parr A, Niggeweg R, Bailey P, Weisshaar B, Martin C. 2008. AtMYB12 regulates caffeoyl quinic acid and flavonol synthesis in tomato: expression in fruit results in very high levels of both types of polyphenol. Plant J. 56(2):316-26.

Lusk JL, Rozon A. 2006. Consumer acceptance of ingenic foods. Biotechnol J 1(12):1433-4.

Moskowitz HR, Muñoz AM, Gacula MC. 2003. Viewpoints and Controversies in Sensory Science and Consumer Product Testing: Food \& nutrition Press, Inc. 
Muir SR, Collins GJ, Robinson S, Hughes S, Bovy A, Vos CHRD, Tunen AJv, Verhoeyen ME. 2001. Overexpression of petunia chalcone isomerase in tomato results in fruit containing increased levels of flavonols Nat Biotechonol 19:470-4.

Murashige T, Skoog F. 1962. A revised medium for rapid growth and bio assays with tobacco tissue cultures. Physiol Plant 15(3):473-97.

Nap J-P, Metz PL, Escaler M, Coner AJ. 2003. The release of genetically modified crops into the environment. Plant J 33(1):1-18.

Park SH, Morris JL, Park JE, Hirschi KD, Smith RH. 2003. Efficient and genotype-independent Agrobacterium - mediated tomato transformation. J Plant Physiol 160:1253-7.

Rao A. 2002. Lycopene, tomatoes, and the prevention of coronary heart disease. Exp Bio Med (Maywood) 227(10):908-13.

Solfanelli C, Poggi A, Loreti E, Alpi A, Perata P. 2006. Sucrose-specific induction of the anthocyanin biosynthetic pathway in Arabidopsis. Plant Physiol 140(2):637-46.

Verhoeyen ME, Bovy A, Collins G, Muir S, Robinson S, de Vos CHR, Colliver S. 2002. Increasing antioxidant levels in tomatoes through modification of the flavonoid biosynthetic pathway. J Exp Bot 53(377):2099-106.

Wach A, Pyrzynska K, Biesaga M. 2007. Quercetin content in some food and herbal samples. Food Chem. 100(2):699-704. 
Willits MG, Kramer CM, Prata RTN, De Luca V, Potter BG, Steffens JC, Graser G. 2005. Utilization of the genetic resources of wild species to create a nontransgenic high flavonoid tomato. J Agri Food Chem 53(4):1231-6.

\section{Author Contributions}

Wansang Lim collected data and drafted the manuscript. Rebecca Miller designed sensory analysis and edited the manuscript. Jungeun Park generated transgenic plants. Sunghun Park designed and supported overall experiments.

Table 1. Mean liking scores and $p$-values of responses from an untrained consumer panel, comparing wild-type (non transgenic), $\mathrm{CHI}$ (high flavonol) and Del/Ros (high anthycyanin) tomatoes. $^{\text {a }}$

\begin{tabular}{|c|c|c|c|c|c|}
\hline & \multirow[b]{2}{*}{ Tomato } & \multicolumn{3}{|c|}{ Liking Score $^{\mathrm{b}}$} & \multirow[b]{2}{*}{ Overall } \\
\hline & & Color & Flavor & Texture & \\
\hline \multirow{3}{*}{ Mean } & Wild-type & $5.41 \mathrm{a}$ & $5.00 \mathrm{~b}$ & $5.13 \mathrm{a}$ & $5.08 \mathrm{~b}$ \\
\hline & $\mathrm{CHI}$ & $5.62 \mathrm{a}$ & $5.51 \mathrm{a}$ & $5.37 a$ & $5.48 a$ \\
\hline & Del/Ros & $5.28 \mathrm{a}$ & $4.84 \mathrm{~b}$ & $5.2 \mathrm{a}$ & $4.9 \mathrm{~b}$ \\
\hline \multirow{3}{*}{ P-value } & Genes & 0.16 & 0.01 & 0.09 & 0.04 \\
\hline & Ripeness & 0.32 & 0.12 & 0.17 & 0.17 \\
\hline & Genes x Ripeness & 0.96 & 0.78 & 0.12 & 0.18 \\
\hline
\end{tabular}

a evaluated by 81 consumers 
${ }^{b}$ on a 7-point scale where 1 = dislike extremely, $4=$ neither like nor dislike, $7=$ like extremely

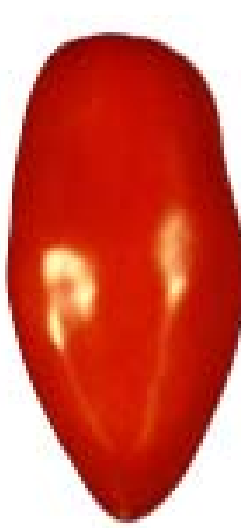

Wild

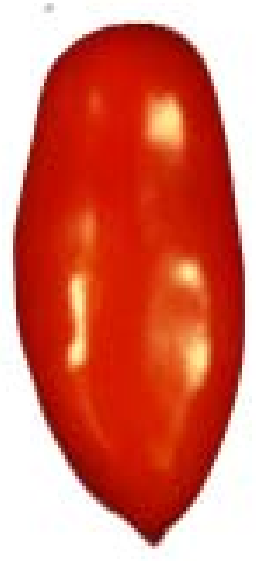

$\mathrm{CHI} \quad$ Del/Ros

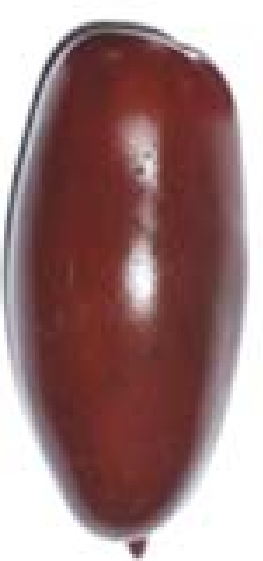

ank

Figure 1. Photograph of non transgenic and transgenic Rubion cultivar tomatoes: Wild =wildtype (non transgenic), $\mathrm{CHI}=$ increased flavonol content using $\mathrm{CHI}$ gene from onion; Del/Ros = increased anthocyanin content using Delila and Roseal genes from snapdragon 


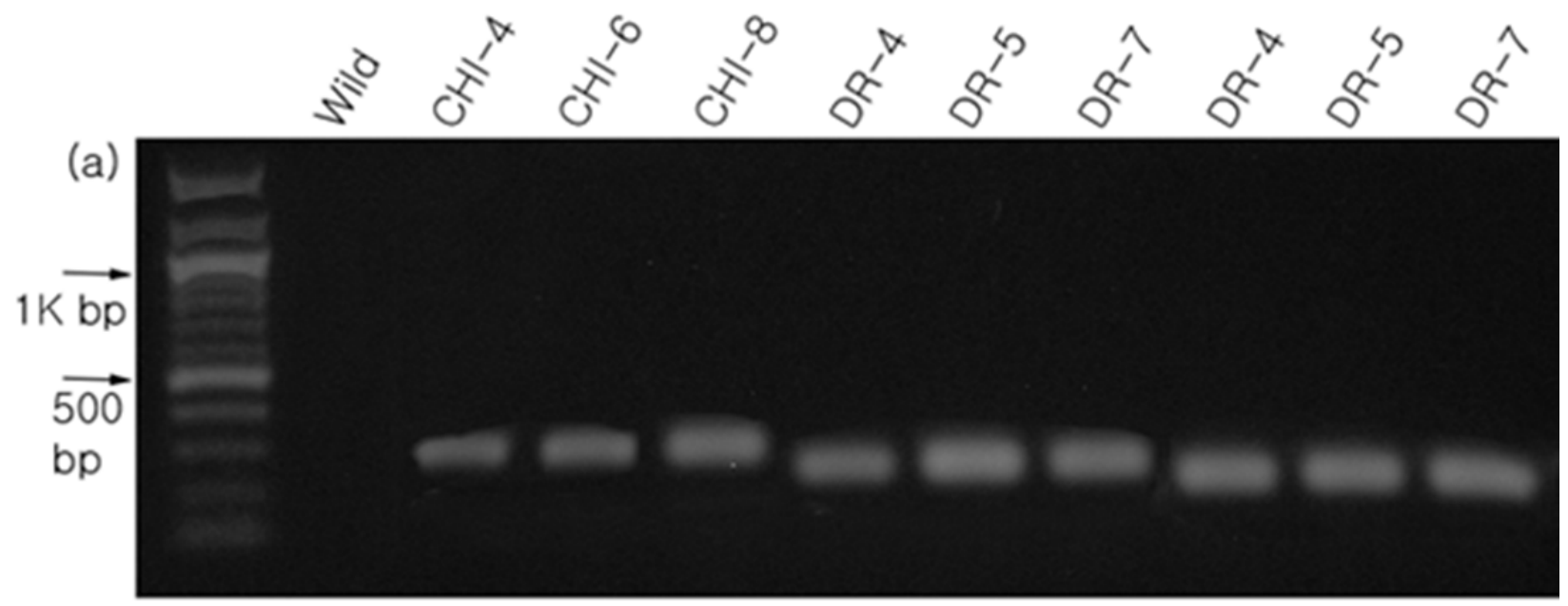

(b) Peel $\square$

$\mathrm{CHI}$ primer

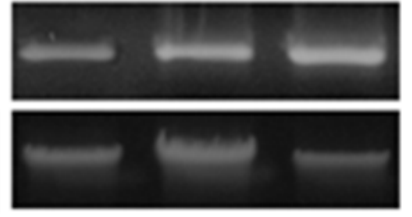

Del primer
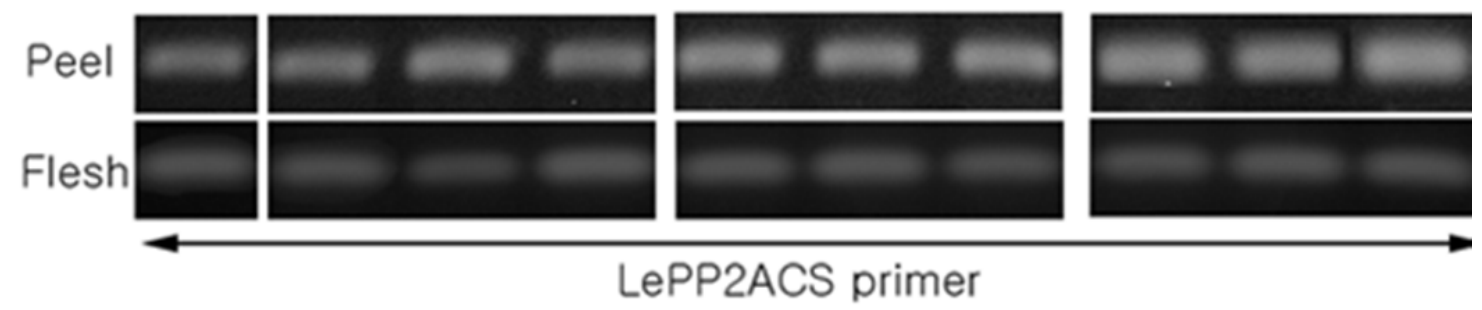

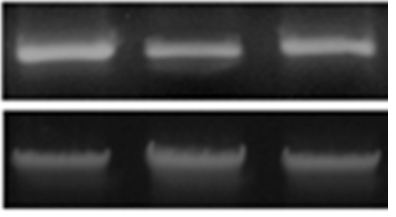

Ros primer

(c) 
Figure 2. Molecular analyses of T1 transgenic plants: (a) genomic DNA PCR from leaf, (b) reverse transcriptase PCR (RT-PCR) for each of the $\mathrm{CHI}$ and Del/Ros lines to check for $\mathrm{CHI}$ and Del/Ros expression, (c) reverse transcriptase PCR (RT-PCR) for each of the $\mathrm{CHI}$ and Del/Ros lines with a housekeeping gene primer (PePP2ACS).
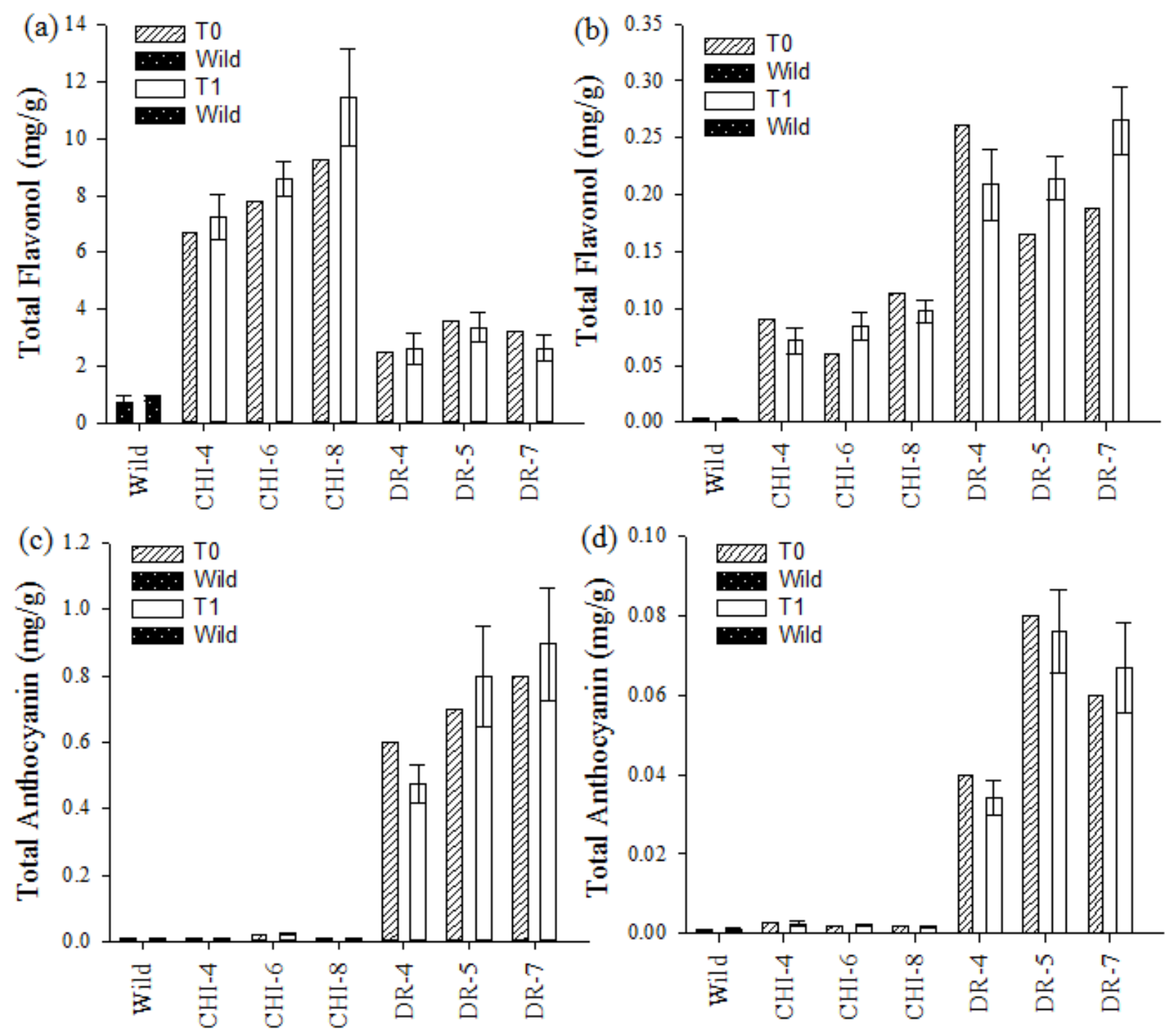

(d) 0.10 T0

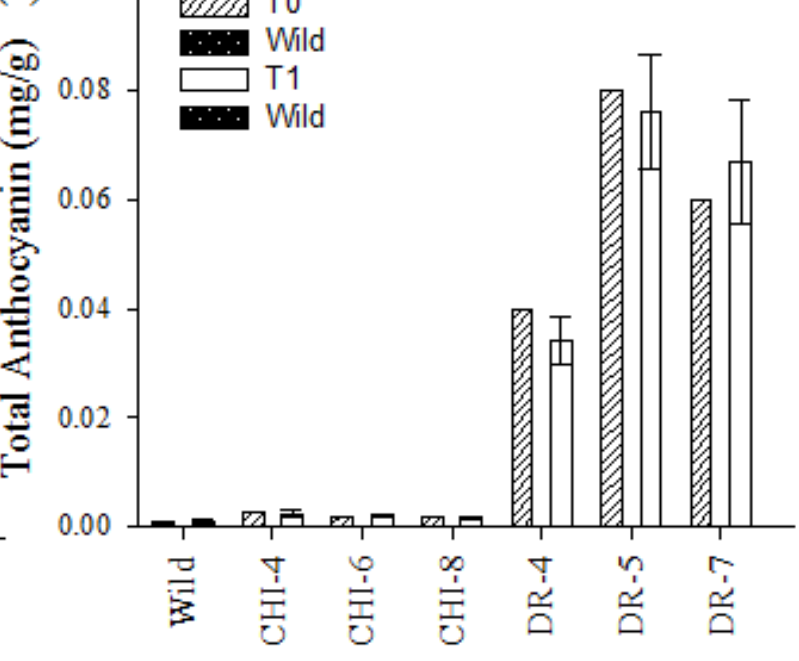

Figure 3. Total flavonol content in (a) peel and (b) flesh and total anthocyanin content in (c) peel and (d) flesh in tomato from T0 and T1 transformants expressing $\mathrm{CHI}$ and Del/Ros. 
Tomatoes were harvested 20 days after breaker stage. The data represent the mean values $( \pm$ SD) derived from 4 plants per each line (2 - 3 tomatoes per plant). 